\title{
Analisis Risiko Keselamatan dan Kesehatan Kerja (K3) pada Pengoperasian Overhead Crane Menggunakan Metode SWIFT (Structured What If Technique) di PT. ABC
}

\author{
Muhamad Bob Anthony \\ Teknik Industri Universitas Serang Raya \\ Jalan Raya Cilegon Km.5 Banten 42162, Indonesia \\ tonipbmti@gmail.com
}

Dikirimkan: 03, 2020. Diterima: 03, 2020. Dipublikasikan: 03, 2020.

\begin{abstract}
PT. ABC is one of the national steel industry companies that has a steel production capacity of three million tons more steel per year and the crane is one of the main equipment used at PT. ABC. Crane has a function as a lifting equipment used to move an object or item from one place to another and the type of crane used at PT. ABC is a type of overhead crane. The use of overhead cranes has various potential hazards both during the routine and non-routine lifting process so that the use of overhead cranes has a very high risk of work accidents. From accident data on overhead crane operations at PT. ABC, there were 27 accident cases from 2016 - 2018 that showed the high level of work accidents that occurred. The SWIFT (Structural What If Analysis) method is a technique for identifying hazards by asking what if keywords. The purpose of this study was to determine the dangers and risks of overhead crane operations at PT. ABC and provide recommendations for improvements to reduce the level of risk of work accidents. Analysis of the worksheet using the SWIFT (structural what if analysis) method produces 18 potential hazards in overhead crane operations and based on RRN (Risk Rating Number) calculations, there are 9 main priority hazards, 5 medium priority hazards, 2 low priority hazards and 2 priority hazards the lowest. Improvement recommendations are made based on the level of risk with the highest priority to prevent and reduce the risk of work accident in overhead crane operations.
\end{abstract}

Keywords-Overhead crane, Potential hazard, Risk Rating Number, SWIFT.

\begin{abstract}
Abstrak - PT. ABC merupakan salah satu perusahaan industri baja nasional yang mempunyai kapasitas produksi baja sebesar tiga juta ton lebih baja per tahunnya dan crane merupakan salah satu peralatan utama yang digunakan di PT. ABC. Crane memiliki fungsi sebagai pesawat angkat angkut yang digunakan untuk memindahkan suatu benda atau barang dari tempat yang satu ke tempat lainnya dan jenis crane yang digunakan di PT. ABC adalah jenis overhead crane. Penggunaan overhead crane mempunyai berbagai potensi bahaya baik itu saat proses pengangkatan yang bersifat rutin maupun non rutin sehingga penggunaan overhead crane memiliki risiko kecelakaan kerja yang sangat tinggi. Dari data kecelakaan pada pengoperasian overhead crane di PT. ABC terdapat 27 kasus kecelakaan dari tahun 2016 - 2018 yang menunjukkan masih tingginya tingkat kecelakaan kerja yang terjadi. Metode SWIFT (Structural What If Analysis) adalah suatu teknik untuk mengidentifikasi bahaya dengan pendekatan bertanya menggunakan kata kunci what if (bagaimana jika). Tujuan penelitian ini untuk mengetahui bahaya dan risiko pada pekerjaan pengoperasian overhead crane di PT. ABC serta memberikan rekomendasi perbaikan untuk mengurangi tingkat risiko kecelakaan kerja. Analisa lembar kerja menggunakan Metode SWIFT (structural what if analysis) menghasilkan 18 potensi bahaya pada pekerjaan pengoperasian overhead crane dan berdasarkan perhitungan RRN (Risk Rating Number), terdapat 9 bahaya prioritas utama, 5 bahaya prioritas menengah, 2 bahaya prioritas rendah dan 2 bahaya prioritas paling rendah. Rekomendasi perbaikan dibuat berdasarkan tingkat risiko dengan prioritas utama untuk mencegah dan mengurangi tingkat risiko kecelakan kerja pada pengoperasian overhead crane.
\end{abstract}

Kata kunci-Overhead crane, Potensi bahaya, Risk Rating Number, SWIFT. 


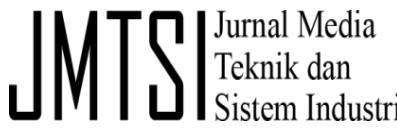

\section{PENDAHULUAN}

PT. ABC merupakan salah satu perusahaan industri baja nasional yang mempunyai kapasitas produksi baja sebesar tiga juta ton lebih baja per tahunnya dan crane merupakan salah satu peralatan utama yang digunakan di PT. ABC. Crane memiliki fungsi sebagai pesawat angkat angkut yang digunakan untuk memindahkan suatu benda atau barang dari tempat yang satu ke tempat lainnya dan jenis crane yang digunakan di PT. $\mathrm{ABC}$ adalah jenis overhead crane.

Penggunaan overhead crane mempunyai berbagai potensi bahaya baik itu saat proses pengangkatan yang bersifat rutin maupun non rutin sehingga penggunaan overhead crane memiliki risiko kecelakaan kerja yang sangat tinggi. Potensi bahaya pada pengoperasian overhead crane diantaranya tabrakan antar crane, crane menabrak fasilitas, pekerja dibawah tertimpa atau tertabrak overhead crane, terjatuh dari ketinggian saat melakukan pengecekan atau perbaikan dan masih banyak lagi potensi bahaya yang belum teridentifikasi dan terukur secara lengkap merupakan permasalahan di area kerja pengoperasian overhead crane.

Faktor keselamatan kerja memegang peranan yang sangat penting dalam suatu perusahaan/industri. Oleh karna itu, banyak yang harus diperhatikan dan dijaga agar perusahaan mampu mengantisipasi terjadinya kecelakaan akibat kerja sedini mungkin, yaitu timbulnya kecelakaan yang berhubungan dengan aktivitas kerja, baik secara langsung maupun secara tidak langsung di perusahaan [1].

Metode yang dapat digunakan untuk mengurangi risiko kecelakaan kerja yang tinggi pada penggunaan atau pengoperasian sebuah peralatan utama dan kritikal adalah metode $S W I F T$ (Structured What If Technique). Metode SWIFT adalah suatu teknik untuk mengidentifikasi bahaya dengan pendekatan bertanya menggunakan kata kunci what if (bagaimana jika). Keberhasilan dalam penggunaan metode SWIFT dipengaruhi oleh pengetahuan pengguna atas sistem dan proses yang di analisis [2].

Laporan kerja SWIFT dibuat sampai penilaian risiko dengan menghitung nilai $R R N$ (Risk Rating Number). Hasil perhitungan RRN ini dapat mengetahui potensi bahaya yang mempunyai nilai risiko paling tinggi (high risk) sampai nilai risiko paling rendah (low risk) [3]. Dengan demikian dapat dilakukan penanganan yang tepat sebagai usaha untuk mencegah terjadinya kecelakaan kerja dan dapat memberikan usulan rekomendasi perbaikan untuk mengurangi risiko kecelakaan kerja pada pengoperasian overhead crane.

Tujuan penelitian ini adalah mengetahui potensi bahaya apa saja yang ada di overhead crane dengan menggunakan metode What If Analysis, mengetahui risiko kecelakaan kerja yang ada pada pengoperasian overhead crane dan memberikan rekomendasi perbaikan yang menjadi prioritas utama pada pengoperasian overhead crane.

TABEL I

DATA KECELAKAAN KERJA PADA PENGOPERASIAN OVERHEAD CRANE DI PT. ABC

\begin{tabular}{|c|c|c|c|}
\hline Tahum & Jenis Kecelakaan & $\begin{array}{c}\text { Jumlah } \\
\text { Kecelakaan }\end{array}$ & Total \\
\hline \multirow{4}{*}{2016} & $\begin{array}{l}\text { Tabrakan antar Overhead } \\
\text { Crans }\end{array}$ & 2 & \multirow{4}{*}{9} \\
\hline & Menabrak fasilitas lain & 5 & \\
\hline & Jari terjepit pada wire ring & 1 & \\
\hline & $\begin{array}{l}\text { Wire Rope putus saat } \\
\text { sedang melakukan } \\
\text { pengangkatan }\end{array}$ & 1 & \\
\hline \multirow{4}{*}{2017} & $\begin{array}{l}\text { Tabrakan antar Overhead } \\
\text { Crane }\end{array}$ & 3 & \multirow{4}{*}{8} \\
\hline & Menabrak fasilitas lain & 5 & \\
\hline & Sticking Slab & 1 & \\
\hline & $\begin{array}{l}\text { Terjatuh saat naik dan } \\
\text { turun dari tangga Overhead } \\
\text { Crane }\end{array}$ & 2 & \\
\hline \multirow{3}{*}{2018} & Menabrak fasilitas lain & 4 & \multirow{3}{*}{11} \\
\hline & $\begin{array}{l}\text { Terjatuh saat turun dari } \\
\text { tangga Overhead Crane }\end{array}$ & 1 & \\
\hline & Slab teriatuh akibat sticking & 2 & \\
\hline
\end{tabular}

\section{Metodologi Penelitian}

Objek penelitian ini adalah overhead crane di PT. ABC. Sumber data yang digunakan berasal dari data primer dan data sekunder yang diperoleh dari tempat penelitian

Pengolahan data dalam penelitian ini menggunakan metode SWIFT (Structured What If Technique) yang terdiri dari mengidentifikasi bahaya dan penilaian tingkat risiko dengan menghitung nilai $R R N$ (Risk Rating Number) [3]. Identifikasi bahaya menggunakan What If Analysis adalah dengan pendekatan bertanya menggunakan kata kunci "what if (bagaimana jika)" untuk mengidentifikasi potensi bahaya pada pekerjaan pengoperasian overhead crane dan menilai kemungkinan serta konsekuensi dari situasi yang terjadi. Jawaban pertanyaan merupakan risiko dari bahaya tersebut dan acuan 
dalam membuat penilaian risiko serta menentukan batas wajar risiko tersebut. Program tindakan berupa safeguard bagi setiap risiko yang

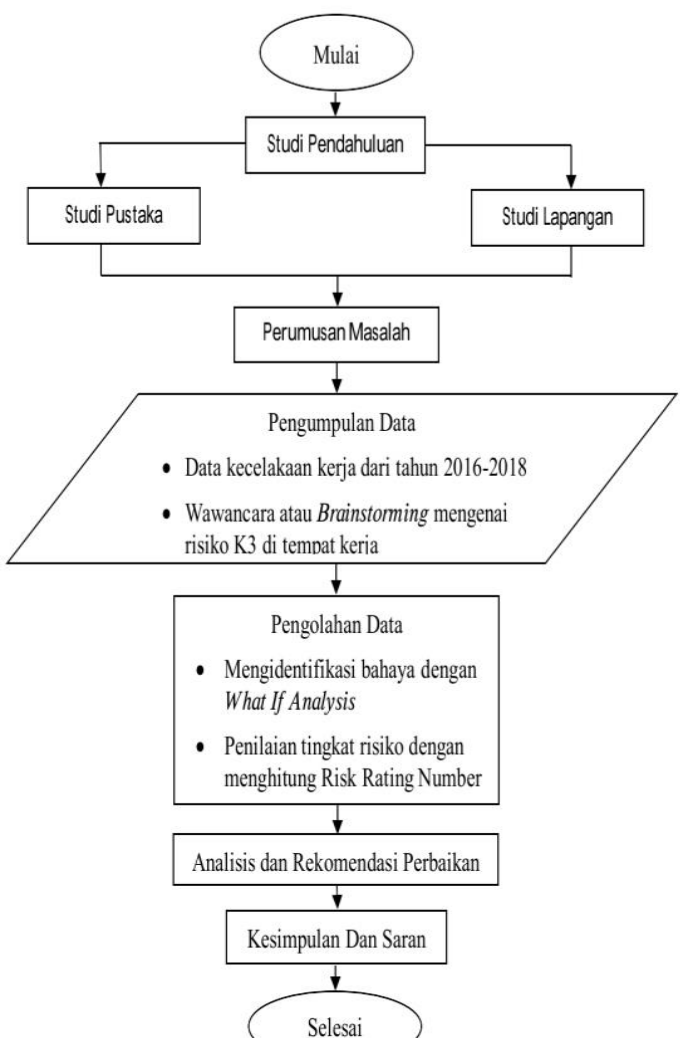

Gambar 1. Diagram alir penelitian

didapatkan berdasarkan jawaban dari risiko tesebut [4].

TABEL II

WHAT IF ANALYSIS

\begin{tabular}{|c|l|l|l|l|}
\hline $\begin{array}{c}\text { What } \\
\text { If }\end{array}$ & Answer & Probability & Consequences & Sqfeguard \\
\hline & & & & \\
& & & & \\
& & & & \\
\hline
\end{tabular}

Penilaian tingkat risiko dilakukan dengan menghitung RRN. Pada tahapan ini proses penilaian tingkat risiko memperhatikan dua aspek yaitu keparahan (severity) dan frekuensi (frequency). Keparahan (severity) diukur berdasarkan tingkat keparahan yang terjadi dan dibagi ke dalam empat kategori [3].
TABEL III

KLASIFIKASI TINGKAT KEPARAHAN (SEVERITY) BAHAYA

\begin{tabular}{|c|c|c|c|}
\hline Description & Category & Score & Definition \\
\hline Catastrophic & I & 4 & $\begin{array}{c}\text { Kematian atau } \\
\text { kehilangan gistem }\end{array}$ \\
\hline \multirow{3}{*}{ Critical } & \multirow{3}{*}{ II } & \multirow{3}{*}{3} & $\begin{array}{c}\text { Luka berat atau cedera } \\
\text { yang menyebabkan } \\
\text { cacat permanen }\end{array}$ \\
\hline & & & $\begin{array}{c}\text { Penyakit akibat kerja } \\
\text { yang parah }\end{array}$ \\
\hline & & & $\begin{array}{c}\text { Kerusakan sistem yang } \\
\text { berat }\end{array}$ \\
\hline \multirow{3}{*}{ Marginal } & \multirow{3}{*}{ III } & \multirow{3}{*}{2} & $\begin{array}{l}\text { Luka sedang, hanya } \\
\text { membutuhkcan } \\
\text { perawatan medis }\end{array}$ \\
\hline & & & $\begin{array}{c}\text { Penyakit akibat kerja } \\
\text { yang ringan }\end{array}$ \\
\hline & & & $\begin{array}{c}\text { Kerusakan sebagian } \\
\text { sistem }\end{array}$ \\
\hline \multirow[t]{2}{*}{ Neglicable } & \multirow[t]{2}{*}{ IV } & \multirow[t]{2}{*}{0,1} & $\begin{array}{l}\text { Luka ringan yang } \\
\text { hanya membutuhkcan } \\
\text { pertolongan pertama }\end{array}$ \\
\hline & & & $\begin{array}{c}\text { Kerusakan sebagian } \\
\text { kecil gistem }\end{array}$ \\
\hline
\end{tabular}

Frekuensi (frequency) merupakan aspek yang menilai seberapa banyak dan seberapa seringnya potensi bahaya yang terjadi. Frekuensi terjadinya potensi bahaya dapat diklasifikasikan berdasarkan banyaknya bahaya yang terjadi, Klasifikasi frekuensi bahaya dapat dilihat pada Tabel IV berikut ini [3].

TABEL IV

KLASIFIKASI FREKUENSI PAPARAN BAHAYA

\begin{tabular}{|c|c|c|c|}
\hline Description & Level & Score & Specific Individual Item \\
\hline Frequent & A & 5 & $\begin{array}{c}\text { Sering terjadi, berulang kali } \\
\text { dalam sistem }\end{array}$ \\
\hline Probable & B & 4 & $\begin{array}{c}\text { Terjadi beberapa kali dalam } \\
\text { siklus sistem }\end{array}$ \\
\hline Occasional & C & 3 & $\begin{array}{c}\text { Terjadi kadang-kadang } \\
\text { dalam siklus sistem }\end{array}$ \\
\hline Remote & D & 2 & $\begin{array}{c}\text { Tidak pemah terjadi, tetapi } \\
\text { mungkin terjadi dalam siklus } \\
\text { sistem }\end{array}$ \\
\hline Improbable & E & 1 & $\begin{array}{c}\text { Tidak Mungkin, dapat } \\
\text { diasumsikan tidak akan } \\
\text { pernah terjadi dalam sistem }\end{array}$ \\
\hline
\end{tabular}

Nilai RRN (Risk Rating Number) dihitung dengan persamaan (1) berikut ini [3] :

$R R N=D P H x L O$

Keterangan :

RRN : Risk Rating Number

DPH : Degree of Possible (Severity) 
LO : Likelihood of Occurance (Frequency)

Tingkat atau prioritas risiko setelah melakukan perhitungan RRN (Risk Rating Number) dapat dilihat pada Tabel V di bawah ini [3].

TABEL V

PRIORITAS RISIKO

\begin{tabular}{|c|c|}
\hline RRN & Tingkat Risiko \\
\hline $0,1-0,3$ & Prioritas paling rendah \\
\hline $0,4-4,0$ & Prioritas rendah/risiko rendah \\
\hline $6,0-9,0$ & Prioritas menengah / risiko yang signifikan \\
\hline$>10$ & Prioritas utama / dibutuhkan tindakan secepatnya \\
\hline
\end{tabular}

Tahapan selanjutnya setelah melakukan perhitungan tingkat risiko dengan menghitung nilai $R R N$ adalah melakukan analisis tingkat risiko melalui pengelompokkan dan membuat rekomendasi perbaikan untuk mencegah dan mengurangi tingkat risiko kecelakaan kerja pada pengoperasian overhead crane berdasarkan tingkat risiko dengan prioritas utama dari hasil peta prioritas risiko tersebut.

\section{HASIL PENELITIAN}

\section{A. Potensi Bahaya Kecelakaan Kerja}

Potensi kecelakaan kerja merupakan suatu risiko kecelakaan yang mungkin akan terjadi dalam sebuah pekerjaan. Di bawah ini merupakan data-data potensi bahaya kecelakaan kerja pada pengoperasian overhead crane yang didapat dari hasil penelitian dan wawancara dengan karyawan perusahaan.

\section{B. Pengolahan Data}

Pengolahan data dalam penelitian ini dengan menggunakan metode Structured What if Technique (SWIFT) yang terdiri dari identifikasi bahaya dengan What if Analysis, memberikan penilaian tingkat risiko dengan menghitung nilai RRN (Risk Rating Number) dan memberikan rekomendasi perbaikan untuk mencegah dan mengurangi tingkat risiko kecelakaan kerja pada pengoperasiaan overhead crane.
TABEL VI

DATA POTENSI BAHAYA PENGOPERASIAN OVERHEAD CRANE

\begin{tabular}{|c|c|}
\hline Altivitits Pekrejuan & Potensi Bahayg \\
\hline Naik dan trum tangga cale & Tersandumg \\
\hline Pengecelan electical room & Tersengat livan listil: \\
\hline 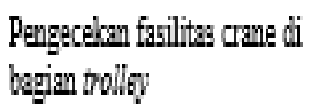 & Terjatth dari ketingegan \\
\hline \multirow{4}{*}{ Mengoperasikan alat } & 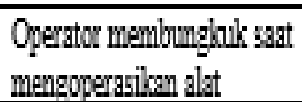 \\
\hline & 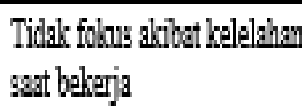 \\
\hline & Tabrakan antar ane \\
\hline & Grane rusak atial mati \\
\hline \multirow{4}{*}{ Melalokan penganghatan } & Grameroboh \\
\hline & Grane triblalkar \\
\hline & $\begin{array}{l}\text { Behan yang dianghat } \\
\text { meleohihi kapasitas }\end{array}$ \\
\hline & Ketingejem cave tidak amar \\
\hline \multirow{2}{*}{ Rigger:Sn } & Tertabrak anase \\
\hline & Terjepit wire ming \\
\hline \multirow{2}{*}{ Saat melakulkan clowing } & Menghinup deou \\
\hline & Tersunghat \\
\hline \multirow{3}{*}{ Sast. Minutewno } & Tertimpa hnci-hurci alat. \\
\hline & 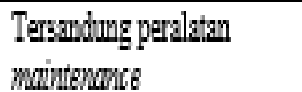 \\
\hline & Teryangat alizan listrik \\
\hline
\end{tabular}


TABEL VII

WHAT IF ANALYSIS PADA PENGOPERASIAN OVERHEAD CRANE

\begin{tabular}{|c|c|c|c|c|c|}
\hline & & & & & \\
\hline If & Thatif & ANSWI & Pindwiting & Consonelases & Stgeraul \\
\hline & 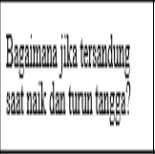 & 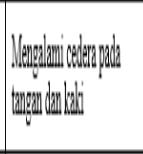 & Powlle & Vimon & 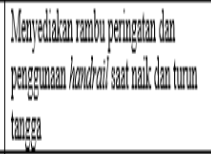 \\
\hline & 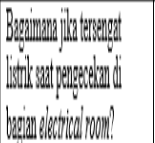 & 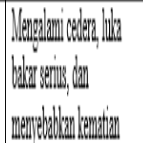 & Powlle & 湘 & 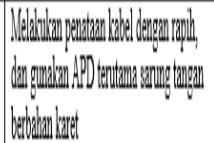 \\
\hline & 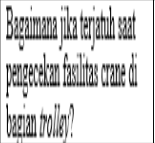 & 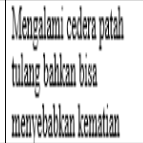 & Powly: & 细 & 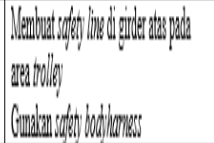 \\
\hline d & 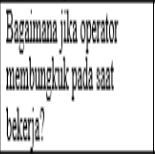 & 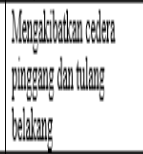 & Provelle & Senons & 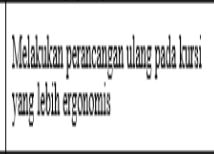 \\
\hline & 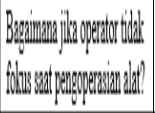 & 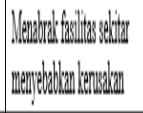 & Poxylle: & binous & 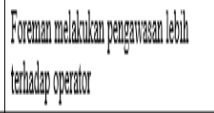 \\
\hline l & 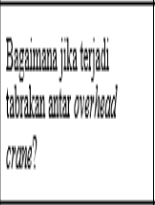 & 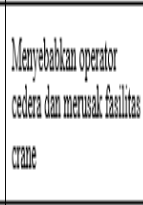 & Prosulte & 的 & 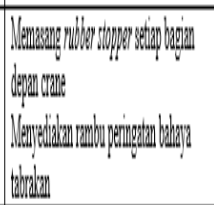 \\
\hline & 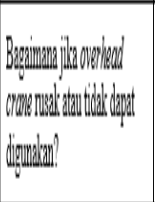 & 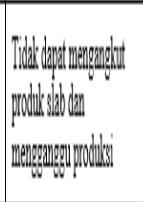 & Prosule & Seriols & 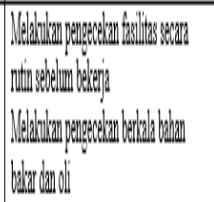 \\
\hline 8 & 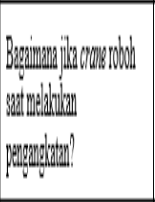 & 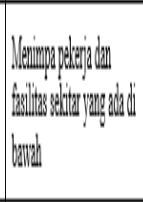 & Wulley & : 981 & 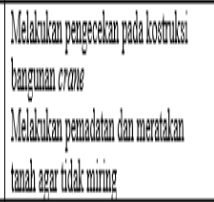 \\
\hline 9 & 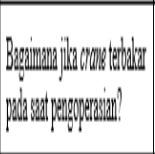 & 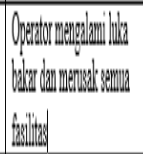 & Willey & 96 & 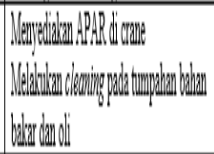 \\
\hline
\end{tabular}

\begin{tabular}{|c|c|c|c|c|c|}
\hline 10 & Thullf & Anwer & Probolitidy & Conservaluess & Safgequal \\
\hline 10 & 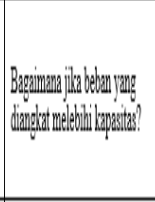 & 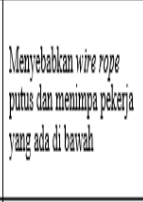 & Prostle & F湘 & 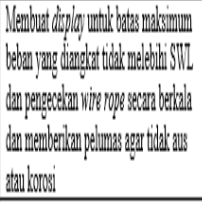 \\
\hline 11 & 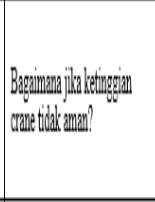 & 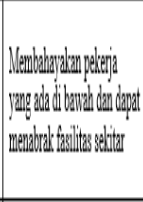 & $\begin{array}{l}\text { Puter } \\
\text { Provlle }\end{array}$ & Serious & 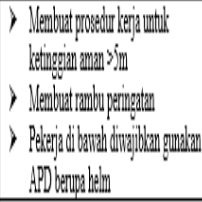 \\
\hline 12 & 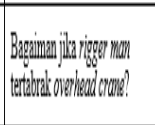 & 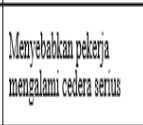 & Prostle & F湖 & 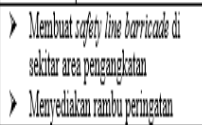 \\
\hline 13 & 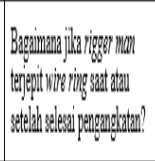 & 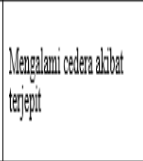 & Posille & Miror & 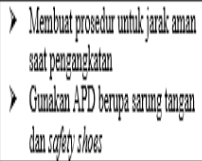 \\
\hline HA & 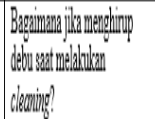 & 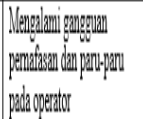 & Prostle & Serous & 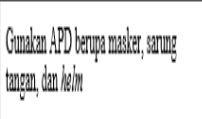 \\
\hline 15 & 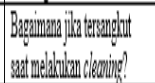 & 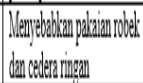 & \begin{tabular}{|l} 
Quith \\
Puille
\end{tabular} & Niror & 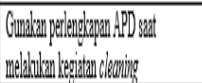 \\
\hline & 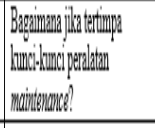 & 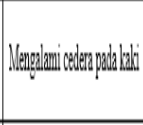 & $\begin{array}{c}\text { Putet } \\
\text { Posille }\end{array}$ & Niror & 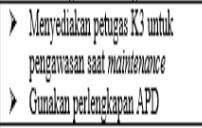 \\
\hline & 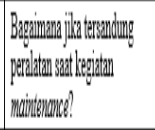 & 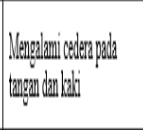 & $\begin{array}{l}\text { (uite } \\
\text { Proville }\end{array}$ & Niror & 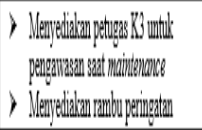 \\
\hline 18 & 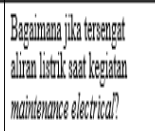 & 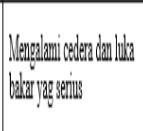 & Proville & Fital & 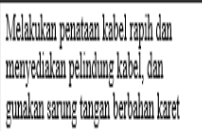 \\
\hline
\end{tabular}

Penelitian ini dilakukan di area pengoperasian overhead crane dikarenakan persentase kecelakaan kerja yang terjadi pada pengoperasian overhead masih sangat tinggi.

Identifikasi bahaya dalam pengoperasian overhead crane dilakukan dengan menggunakan what if analysis. What if Analysis adalah identifikasi bahaya dengan pendekatan bertanya yang menggunakan kata kunci "what if (bagaimana jika)" untuk mengidentifikasi bahaya.

Tabel VII merupakan worksheet What if Analysis pengoperasian overhead crane di PT. ABC. Worksheet ini menjelaskan tingkat keparahan (severity), frekuensi (frequency) dan safeguard dari masing -masing potensi bahaya.

Penilaian tingkat risiko menggunakan dua aspek yaitu keparahan (severity) dan frekuensi (frequency). Penilaian tingkat risiko tersebut dilakukan dengan menghitung Risk Rating Number $(R R N)$ yang dapat dilihat pada Tabel VIII dibawah ini. 


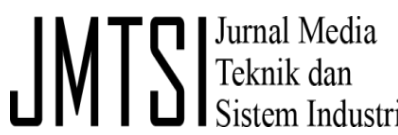

TABEL VIII

PERHITUNGAN $R R N$ PADA PENGOPERASIAN OVERHEAD CRANE

\begin{tabular}{|c|c|c|c|c|c|c|}
\hline \multirow{2}{*}{$\operatorname{lng}$} & \multicolumn{2}{|c|}{ Keparhan (y) } & \multicolumn{2}{|c|}{ Fenes (I) } & \multirow{2}{*}{ Bili } & \multirow{2}{*}{ Pinith } \\
\hline & Magni & Nili & Kiguni & Filli & & \\
\hline Ponding & III & $!$ & 5 & : & 6 & hindyand \\
\hline 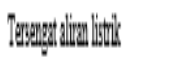 & I & $\downarrow$ & $D$ & 1 & 8 & 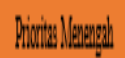 \\
\hline 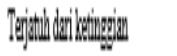 & ! & $\phi$ & 0 & 1 & 8 & Haxy bey \\
\hline 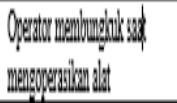 & II & $i$ & $A$ & ; & i & Hund Ines \\
\hline 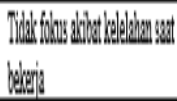 & 【 & $i$ & $A$ & ; & $\$$ & hindy lhese \\
\hline Tomole way & $\llbracket$ & i & 8 & 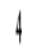 & 11 & hindel lane \\
\hline 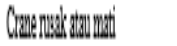 & II & i & 8 & $\not$ & 11 & Mingl|hes \\
\hline Wanend & I & $\downarrow$ & D & 1 & 8 & hotolyened \\
\hline 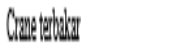 & i & $\phi$ & C & : & 11 & Ming \\
\hline 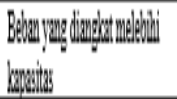 & i & $\phi$ & 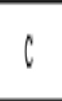 & ; & 11 & hind 1 has \\
\hline Why diswa & II & $i$ & D & 1 & 1 & 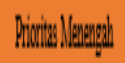 \\
\hline Podudar. & 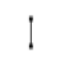 & $\phi$ & 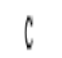 & : & 11 & hindthering \\
\hline Prondwy & II & $\|$ & 6 & : & D: & 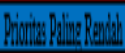 \\
\hline Nyodind dew & II & i & $A$ & ; & $j$ & hund lane \\
\hline mand & II & 11 & 6 & : & $0:$ & Dhing Ding prish \\
\hline 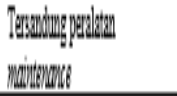 & III & 1 & D & 1 & 1 & Mund Pand \\
\hline 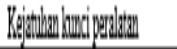 & III & $!$ & D & 1 & 4 & Manis Ped \\
\hline 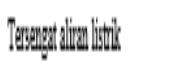 & I & $\phi$ & 6 & : & 11 & 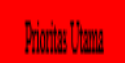 \\
\hline
\end{tabular}

\section{IV.PEMBAHASAN}

Analisis data yang dilakukan adalah melakukan analisis tingkat risiko terhadap hasil pengolahan data pada perhitungan nilai $R R N$ (risk rating number). Analisis tingkat risiko yang dilakukan pada tahap ini adalah dengan melakukan pengelompokkan bahaya yang memiliki tingkat risiko dengan prioritas utama, bahaya dengan tingkat risiko prioritas menengah, bahaya dengan tingkat risiko prioritas rendah dan bahaya dengan tingkat risiko prioritas paling rendah.

Analisis tingkat risiko prioritas utama dapat dilihat pada Tabel IX di bawah ini :

TABEL IX

TINGKAT PRIORITAS UTAMA

\begin{tabular}{|c|c|c|c|}
\hline Hazard & $\begin{array}{l}\text { Tingkat } \\
\text { Prioritas }\end{array}$ & Kategori & Keterengan \\
\hline $\begin{array}{l}\text { Operator } \\
\text { membungk } \\
\text { uk saat } \\
\text { mengopera } \\
\text { sikan alat }\end{array}$ & $\begin{array}{l}\text { Prioritas } \\
\text { Utama }\end{array}$ & $2 \mathrm{~A}$ & $\begin{array}{l}\text { Dapat menimbulkan } \\
\text { cedera yang } \\
\text { menyebablan cacat } \\
\text { permanen dan hal } \\
\text { ini sering terjadi } \\
\text { dalam siklus sistem }\end{array}$ \\
\hline $\begin{array}{l}\text { Tidak } \\
\text { fokus } \\
\text { akibat } \\
\text { kelelahan } \\
\text { saat } \\
\text { bekerja }\end{array}$ & $\begin{array}{l}\text { Prioritas } \\
\text { Utama }\end{array}$ & $2 \mathrm{~A}$ & $\begin{array}{l}\text { Dapat menyebabkan } \\
\text { kerusakan sistem } \\
\text { yang berat dan hal } \\
\text { ini sering terjadi } \\
\text { dalam siklus sistem }\end{array}$ \\
\hline $\begin{array}{l}\text { Tabrakan } \\
\text { antar } \\
\text { crane }\end{array}$ & $\begin{array}{l}\text { Prioritas } \\
\text { Utama }\end{array}$ & $2 \mathrm{~B}$ & $\begin{array}{l}\text { Dapat } \\
\text { mengakibatkan } \\
\text { cedera yang } \\
\text { menyebablan cacat } \\
\text { permanen dan } \\
\text { kerusakan sistem } \\
\text { yang berat, hal ini } \\
\text { terjadi beberapa kali } \\
\text { dalam siklus sistem }\end{array}$ \\
\hline $\begin{array}{l}\text { Crane } \\
\text { rusak atau } \\
\text { mati }\end{array}$ & $\begin{array}{l}\text { Prioritas } \\
\text { Utama }\end{array}$ & $2 \mathrm{~B}$ & $\begin{array}{l}\text { Dapat menyebabkan } \\
\text { kerusakan sistem } \\
\text { yang berat dan hal } \\
\text { ini terjadi beberapa } \\
\text { kali dalam siklus } \\
\text { sistem }\end{array}$ \\
\hline $\begin{array}{l}\text { Crane } \\
\text { terbakar }\end{array}$ & $\begin{array}{c}\text { Prioritas } \\
\text { Utama }\end{array}$ & $1 \mathrm{C}$ & $\begin{array}{l}\text { Dapat menimbulkan } \\
\text { bahaya yang } \\
\text { menyebabkan } \\
\text { kematian dan } \\
\text { kehilangan sistem, } \\
\text { hal ini terjadi } \\
\text { kadang-kadang } \\
\text { dalam siklus sistem }\end{array}$ \\
\hline
\end{tabular}




\begin{tabular}{|l|c|c|c|}
\hline Hozard & $\begin{array}{l}\text { Tingkat } \\
\text { Prioritas }\end{array}$ & Kategori & \multicolumn{1}{|c|}{ Keterengan } \\
\hline $\begin{array}{l}\text { Beban } \\
\text { yang } \\
\text { diangkat } \\
\text { melebihi } \\
\text { kapasitas }\end{array}$ & $\begin{array}{c}\text { Prioritas } \\
\text { Utama }\end{array}$ & 1C & $\begin{array}{l}\text { Dapat menimbulkan } \\
\text { bahaya yang } \\
\text { menyebabkan } \\
\text { kematian dan } \\
\text { kehilangan sistem, } \\
\text { hal ini terjadi } \\
\text { kadang-kadang } \\
\text { dalam siklus sistem }\end{array}$ \\
\hline $\begin{array}{l}\text { Tertabrak } \\
\text { crane }\end{array}$ & $\begin{array}{l}\text { Prioritas } \\
\text { Utama }\end{array}$ & 1C & $\begin{array}{l}\text { Dapat menimbulkan } \\
\text { bahaya yang } \\
\text { menyebabkan } \\
\text { kematian dan hal ini } \\
\text { terjadi kadang- } \\
\text { kadang dalam siklus } \\
\text { sistem }\end{array}$ \\
\hline $\begin{array}{l}\text { Menghiru } \\
\text { p debu }\end{array}$ & $\begin{array}{l}\text { Prioritas } \\
\text { Utama }\end{array}$ & 2A & $\begin{array}{l}\text { Dapat menimbulkan } \\
\text { penyakit akibat } \\
\text { kerja yang parah } \\
\text { dan hal ini sering } \\
\text { terjadi berulang kali } \\
\text { dalam sistem }\end{array}$ \\
\hline $\begin{array}{l}\text { Tersengat } \\
\text { aliran } \\
\text { listrik saat } \\
\text { maintenan } \\
\text { ce }\end{array}$ & Utama & 1C & $\begin{array}{l}\text { Dapat menimbulkan } \\
\text { bahaya yang } \\
\text { menyebabkan } \\
\text { kematian dan } \\
\text { kehilangan sistem, } \\
\text { hal ini terjadi } \\
\text { kadang-kadang } \\
\text { dalam siklus sistem }\end{array}$ \\
\hline
\end{tabular}

Analisis tingkat risiko prioritas menengah dapat dilihat pada Tabel $\mathrm{X}$ berikut ini :

TABEL $X$

TINGKAT PRIORITAS MENENGAH

\begin{tabular}{|c|c|c|c|}
\hline Firaderd & $\begin{array}{l}\text { Tinglat } \\
\text { Prionitas }\end{array}$ & Kategori & Keterengan \\
\hline Tersandung & $\begin{array}{l}\text { Prionitass } \\
\text { Menengah }\end{array}$ & $3 c$ & $\begin{array}{l}\text { Dapat menimbulkan } \\
\text { luka sedang yang } \\
\text { menburuhkan } \\
\text { perawatan medis } \\
\text { dun hal ini terjadi } \\
\text { kadang-kadang } \\
\text { dalam silkhas sistem }\end{array}$ \\
\hline $\begin{array}{l}\text { Tersengat } \\
\text { aliran listrik } \\
\text { saat } \\
\text { pengecekan }\end{array}$ & $\begin{array}{l}\text { Prionitas } \\
\text { Menengah }\end{array}$ & ID & $\begin{array}{l}\text { Dupat menimbulkan } \\
\text { bahaya yang } \\
\text { menychablian } \\
\text { bematian dan } \\
\text { behilangan sistem, } \\
\text { bal ini tidak pernah } \\
\text { serjadi tetapi } \\
\text { mungkin saja serjadi } \\
\text { dalam silahas sistem }\end{array}$ \\
\hline $\begin{array}{l}\text { Terjasuh duri } \\
\text { hetinggian }\end{array}$ & $\begin{array}{l}\text { Prionitas } \\
\text { Menengah }\end{array}$ & ID & $\begin{array}{l}\text { Dapat menimbulkan } \\
\text { bahaya yang } \\
\text { menychablan } \\
\text { kematian dan } \\
\text { behilangan sistem, } \\
\text { hal iai tidak pernah } \\
\text { terjadi tetapi } \\
\text { mungkin saja serjadi } \\
\text { dalam sidhas sistem }\end{array}$ \\
\hline Crane roboh & $\begin{array}{l}\text { Prionitas } \\
\text { Menengah }\end{array}$ & ID & 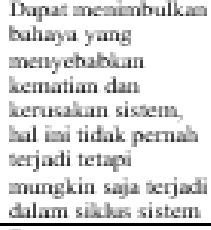 \\
\hline $\begin{array}{l}\text { Ketinggian } \\
\text { tidak aman }\end{array}$ & $\begin{array}{l}\text { Prionitas } \\
\text { Menengeh }\end{array}$ & $2 \mathrm{D}$ & $\begin{array}{l}\text { Dapat } \\
\text { mengakihatkan baka } \\
\text { berat yang } \\
\text { menyebabian cacat } \\
\text { permasen dan hal } \\
\text { ini tidak pennah } \\
\text { serjadi tetapi } \\
\text { mungkin saja serjadi } \\
\text { dalam sildwes sistem. }\end{array}$ \\
\hline
\end{tabular}

Analisis tingkat risiko prioritas rendah dapat dilihat pada Tabel XI berikut ini :

TABEL XI

TINGKAT PRIORITAS RENDAH

\begin{tabular}{|c|c|c|c|}
\hline Hazard & $\begin{array}{l}\text { Tingkat } \\
\text { Prioritas }\end{array}$ & Kategori & Keterenga \\
\hline $\begin{array}{l}\text { Tersandung } \\
\text { peralatan } \\
\text { ntaiklentartes }\end{array}$ & $\begin{array}{c}\text { Priocitas } \\
\text { Rendah }\end{array}$ & 3D & $\begin{array}{l}\text { Dapat menimbulkan } \\
\text { luka sedang yang } \\
\text { menbuatukan } \\
\text { perawatan msedis } \\
\text { dan hal ini tidak } \\
\text { pernah terjadi ietapi } \\
\text { mungkin saja serjadi } \\
\text { dalam sildas sistem }\end{array}$ \\
\hline $\begin{array}{l}\text { Kejatuhan } \\
\text { kursi } \\
\text { peralatan }\end{array}$ & $\begin{array}{c}\text { Proiotas } \\
\text { Rendah }\end{array}$ & 3D & $\begin{array}{l}\text { Dapat menimbulkan } \\
\text { luka sedang yang } \\
\text { menbuahlan } \\
\text { perawatan usedis } \\
\text { dun hal ini tidak } \\
\text { pernah terjadi tetapi } \\
\text { mungkin saja serjadi } \\
\text { dalam sidwas sistem }\end{array}$ \\
\hline
\end{tabular}

Analisis tingkat risiko prioritas paling rendah dapat dilihat pada Tabel XII berikut ini :

TABEL XII

TINGKAT PRIORITAS PALING RENDAH

\begin{tabular}{|c|c|c|c|}
\hline Henard & $\begin{array}{l}\text { Tinglat } \\
\text { Prianitas }\end{array}$ & Kategori & Keserengan \\
\hline $\begin{array}{l}\text { Terjepit } \\
\text { wird ring }\end{array}$ & $\begin{array}{l}\text { Raling } \\
\text { Rendah }\end{array}$ & $4 \mathrm{C}$ & $\begin{array}{l}\text { Dapat menimbulkan } \\
\text { luka ringan yang } \\
\text { banya membutuhkan } \\
\text { periolougan pertama } \\
\text { dan hal ini terjadi } \\
\text { kadang-kadang dalam } \\
\text { siklus sistem }\end{array}$ \\
\hline $\begin{array}{l}\text { Tersangkut } \\
\text { saat } \\
\text { melakukan } \\
\text { cidating }\end{array}$ & $\begin{array}{l}\text { Paling } \\
\text { Rendah }\end{array}$ & $4 \mathrm{C}$ & $\begin{array}{l}\text { Dapat menimbulkan } \\
\text { luka ringan yang } \\
\text { hanya membutuhkan } \\
\text { periolongan pertama } \\
\text { dun hal ini terjadi } \\
\text { kadang-kadang dalam } \\
\text { siklus sistem }\end{array}$ \\
\hline
\end{tabular}

Setelah melakukan analisis tingkat risiko, langkah selanjutnya adalah membuat rekomendasi perbaikan berdasarkan tingkat risiko yang tidak aman atau berbahaya (prioritas utama).

Prioritas utama ini harus dikurangi tingkat risikonya dikarenakan jika tidak dikurangi maka akan sangat berbahaya bagi pekerja, perusahaan dan lingkungan sekitarnya.

Rekomendasi perbaikan untuk pengoperasian overhead crane dengan prioritas utama terdapat pada Tabel XIII dibawah ini : 


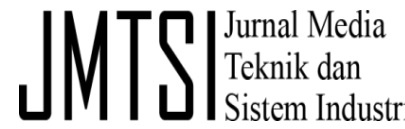

TABEL XIII

REKOMENDASI PERBAIKAN PRIORITAS UTAMA

\begin{tabular}{|c|c|c|}
\hline Hazard & Prioritas & Rekomendasi Perbaikan \\
\hline $\begin{array}{l}\text { Operator } \\
\text { membungkuk } \\
\text { saat } \\
\text { mengoperasikan } \\
\text { alat }\end{array}$ & $\begin{array}{l}\text { Prioritas } \\
\text { Utama }\end{array}$ & $\begin{array}{l}\text { Melakukan perancangan } \\
\text { ulang pada kursi kabin } \\
\text { overhead crane agar lebih } \\
\text { ergonomis }\end{array}$ \\
\hline \multirow{3}{*}{$\begin{array}{l}\text { Tidak fokus } \\
\text { akibat kelelahan } \\
\text { saat bekerja }\end{array}$} & \multirow{3}{*}{$\begin{array}{l}\text { Prioritas } \\
\text { Utama }\end{array}$} & $\begin{array}{l}\text { Supervisor melakukan } \\
\text { pengawasan secara berkala } \\
\text { kepada operator serta } \\
\text { membuat suatu tindakan } \\
\text { atau sanksi bagi operator } \\
\text { yang ceroboh dan tidak } \\
\text { sesuai dengan prosedur } \\
\text { dalam mengoperasikan alat }\end{array}$ \\
\hline & & $\begin{array}{l}\text { Membuat rambu peringatan } \\
\text { untuk tidak bermain } \\
\text { handphone dan mengobrol } \\
\text { saat bekerja }\end{array}$ \\
\hline & & $\begin{array}{l}\text { Memberikan waktu jeda } \\
\text { untuk operator beristirahat } \\
\text { di sela-sela saat } \\
\text { pengoperasian alat }\end{array}$ \\
\hline \multirow{4}{*}{$\begin{array}{l}\text { Tabrakan antar } \\
\text { crane }\end{array}$} & \multirow{4}{*}{$\begin{array}{l}\text { Prioritas } \\
\text { Utama }\end{array}$} & $\begin{array}{l}\text { Melakukan TBM (Tool Box } \\
\text { Meeting) sebelum bekerja }\end{array}$ \\
\hline & & $\begin{array}{l}\text { Harus ada pengawas crane } \\
\text { pada waktu pekerjaan di } \\
\text { mulai }\end{array}$ \\
\hline & & $\begin{array}{l}\text { Menyediakan rambu } \\
\text { peringatan bahaya tabrakan }\end{array}$ \\
\hline & & $\begin{array}{l}\text { Memasang rubber stopper } \\
\text { di setiap bagian depan } \\
\text { overhead crane untuk } \\
\text { meminimalisir benturan } \\
\text { secara langsung }\end{array}$ \\
\hline \multirow{3}{*}{$\begin{array}{l}\text { Crane rusak } \\
\text { atau mati }\end{array}$} & \multirow{3}{*}{$\begin{array}{l}\text { Prioritas } \\
\text { Utama }\end{array}$} & $\begin{array}{l}\text { Melakukan pengecekan } \\
\text { fasilitas crane sebelum } \\
\text { memulai pekerjaan }\end{array}$ \\
\hline & & $\begin{array}{l}\text { Melakukan pengecekan } \\
\text { pada bahan bakar dan oli } \\
\text { secara berkala }\end{array}$ \\
\hline & & $\begin{array}{l}\text { Melakukan preventive } \\
\text { maintenance terutama pada } \\
\text { bagian fasilitas crane }\end{array}$ \\
\hline \multirow{3}{*}{ Crane terbakar } & \multirow{3}{*}{$\begin{array}{l}\text { Prioritas } \\
\text { Utama }\end{array}$} & $\begin{array}{l}\text { Mengisi checklist sebelum } \\
\text { crane digunakan }\end{array}$ \\
\hline & & $\begin{array}{l}\text { Melakukan cleaning pada } \\
\text { tumpahan bahan bakar dan } \\
\text { oli }\end{array}$ \\
\hline & & $\begin{array}{l}\text { Menyediakan APAR di } \\
\text { crane }\end{array}$ \\
\hline \multirow{4}{*}{$\begin{array}{l}\text { Beban yang } \\
\text { diangkat } \\
\text { melebihi } \\
\text { kapasitas }\end{array}$} & \multirow{4}{*}{$\begin{array}{l}\text { Prioritas } \\
\text { Utama }\end{array}$} & $\begin{array}{l}\text { Membuat program alarm } \\
\text { peringatan jika beban yang } \\
\text { diangkat melebihi SWL } \\
\text { (Safe Working Load) }\end{array}$ \\
\hline & & $\begin{array}{l}\text { Melakukan inspelssi berkala } \\
\text { oleh pihak otoritas terkait }\end{array}$ \\
\hline & & $\begin{array}{l}\text { Membuat display batas } \\
\text { maksimum beban yang } \\
\text { diangkat }\end{array}$ \\
\hline & & $\begin{array}{l}\text { Melakukan pengecekan pada } \\
\text { wire rope secara berkala dan } \\
\text { memberikan pelumas agar tidak } \\
\text { aus atau korosi }\end{array}$ \\
\hline
\end{tabular}

\begin{tabular}{|c|c|c|}
\hline Hasard & Prioritas & Rekomendasi Perbaikan \\
\hline \multirow{4}{*}{$\begin{array}{l}\text { Tertabrak } \\
\text { crane }\end{array}$} & \multirow{4}{*}{$\begin{array}{l}\text { Prioritas } \\
\text { Utama }\end{array}$} & $\begin{array}{l}\text { Membuat safety line hard } \\
\text { barricade di sekitar area } \\
\text { pengoperasian overhead } \\
\text { crane }\end{array}$ \\
\hline & & $\begin{array}{l}\text { Menyediakan Handy Talky } \\
\text { untuk alat komunikasi antara } \\
\text { operator dan rigger }\end{array}$ \\
\hline & & $\begin{array}{l}\text { Menyediakan rambu } \\
\text { peringatan aktivitas loading } \\
\text { and wnloading }\end{array}$ \\
\hline & & $\begin{array}{l}\text { Memasang sirine pada crane } \\
\text { sehingga semua pekerja di } \\
\text { bawah tetap waspada }\end{array}$ \\
\hline \multirow[b]{2}{*}{$\begin{array}{l}\text { Menghirup } \\
\text { debu }\end{array}$} & \multirow[b]{2}{*}{$\begin{array}{l}\text { Prioritas } \\
\text { Utama }\end{array}$} & $\begin{array}{l}\text { Menggunakan vacuum } \\
\text { cleaner untuk mengurangi } \\
\text { debu yang bertebaran agar } \\
\text { tidak terhirup }\end{array}$ \\
\hline & & $\begin{array}{l}\text { Menggunakan APD lengkap } \\
\text { berupa masker debu, kaca } \\
\text { mata, sarung tangan, dan } \\
\text { helm pada saat melakukan } \\
\text { cleaning }\end{array}$ \\
\hline \multirow{2}{*}{$\begin{array}{l}\text { Tersengat } \\
\text { aliran listrik }\end{array}$} & \multirow{2}{*}{$\begin{array}{l}\text { Prioritas } \\
\text { Utama }\end{array}$} & $\begin{array}{l}\text { Memasang ELCB (Electric } \\
\text { Leak Circuit Breaker) pada } \\
\text { semua peralatan listrik }\end{array}$ \\
\hline & & $\begin{array}{l}\text { Menggunakan APD terutama } \\
\text { pelindung tangan dan } \\
\text { pelindung kaki yang berbahan } \\
\text { dari karet }\end{array}$ \\
\hline
\end{tabular}

\section{KESIMPULAN}

Berdasarakan hasil penelitian yang telah dilakukan mengenai analisis risiko $\mathrm{K} 3$ (Keselamatan dan Kesehatan Kerja) pada pengoperasian overhead crane dengan metode SWIFT (Structured What if Technique) maka dihasilkan kesimpulan sebagai berikut :

1. Potensi bahaya pada pengoperasian overhead crane adalah tersandung saat naik turun tangga crane, tersengat aliran listrik, terjatuh dari ketinggian, operator membungkuk saat mengoperasikan alat, tidak fokus saat bekerja, tabrakan antar crane, crane rusak, crane roboh, crane terbakar, beban yang diangkat melebihi kapasitas, ketinggian crane tidak aman saat pengangkatan, tertabrak crane, terjepit wire ring, menghirup debu, tersangkut saat cleaning, tertimpa kunci-kunci, tersandung peralatan maintenance, tersengat listrik saat perbaikan elektrik.

2. Berdasarkan hasil penilaian tingkat risiko dengan menghitung nilai $R R N$ (risk rating number) pada semua potensi bahaya pengoperasian overhead crane dihasilkan 9 bahaya yang masuk dalam prioritas utama, 5 prioritas menengah, 2 prioritas rendah dan 2 bahaya masuk dalam prioritas paling rendah. 
3. Rekomendasi perbaikan dibuat berdasarkan tingkat risiko dengan prioritas utama untuk mencegah dan mengurangi tingkat risiko kecelakan kerja pada pengoperasian overhead crane.

\section{REFERENSI}

[1] I. Masrofah and F. Hermawan, "Analisis Pengaruh Kecelakaan Kerja Terhadap Pemenuhan Target Produksi Dengan Regresi Linier di PD Tahu Al-Barokah," J. Media Tek. dan Sist. Ind., vol. 3, no. 2, pp. 95-100, 2019.

[2] Card, J. Alan, et al. (2012). "Beyond FMEA: The Structured What if Technique (SWIFT)." Journal of Healthcare Risk Management. Vol. 31. No.(4). 23-29

[3] Aryanto, Yudi. (2008). "Usulan Program Keselamatan dan Kesehatan Kerja Berdasarkan OHSAS 18001:1999 dan Permenakaer 1996." Institut Teknologi Bandung. Bandung.

[4] Adhi, Sudrajat, et al. (2016). "Analisis Potensi Bahaya Dengan Metode Checklist dan What if Analysis Pada Saat Commissioning Plant N83 di PT. Gas Industri., Program Studi Teknik Keselamatan dan Kesehatan Kerja. Politeknik Perkapalan Surabaya 